\title{
The Lemon Car Game Across Cultures: Evidence of Relational Rationality
}

\author{
Gert Jan Hofstede ${ }^{1}$ D $\cdot$ Catholijn M. Jonker ${ }^{2}$ D $\cdot$ Tim Verwaart $^{3}$. \\ Neil Yorke-Smith ${ }^{2,4}$
}

Published online: 18 July 2019

(c) The Author(s) 2019

\begin{abstract}
In cross-cultural business negotiation, culture is known to influence negotiation processes. As a lens to study this effect we deployed the Lemon Car Game, an online negotiation game developed for this purpose (Hofstede et al. in: Proceedings of 39th international simulation and gaming association conference (ISAGA). Technologia, Kaunas, pp 39-46, 2009a; Hofstede et al. in: David, Sichman (eds) Multi-agentbased simulation IX, international workshop, MABS 2008, revised selectedpapers, LNAI 5269. Springer, Berlin, pp 1-16, 2009b). In this article we report the results from the game, obtained from over 800 players from more than 70 countries. We employ several complementary analyses in a mixed-methods approach. Our findings show that to make sense of the players' actions during negotiation, economic rationality falls short. A pan-cultural individual-level analysis of actions and stated intentions also fails to yield a coherent picture. Within countries, however, actions and intentions do cohere, as shown by an ecological country-level factor analysis, from which three factors emerge for the sellers at country level: trustworthiness, opportunism, and fairness. We conclude from these findings that, in this game, players are driven by what we call relational rationality: they are rational from the perspective of the social world in which they live, with interpersonal relationships weighing heavily. Relational rationality changes players' perspective of economic rationality, and thus their observed behaviour in negotiation. Based on this evidence, we extrapolate that relational rationality significantly influences negotiation processes in all cultures.
\end{abstract}

Keywords Negotiation $\cdot$ Culture $\cdot$ Experimental studies $\cdot$ Power distance $\cdot$ Longterm orientation $\cdot$ Lemon car

Neil Yorke-Smith

n.yorke-smith@tudelft.nl

Extended author information available on the last page of the article 


\section{Introduction}

During business negotiations, navigating issues of trust and transparency is crucial (Hofstede 2006; Hofstede et al. 2006; Turel and Yuan 2008; Irmer and Druckman 2009). We adopt the view that when two people are negotiating a trade deal, implicit assumptions always affect their negotiation behaviour. These assumptions concern their real-world relationship, but also negotiation in general. In globalized trade, further, the context of negotiation is cross-cultural, and misunderstandings may arise if participants misinterpret one another's actions due to differences in norms and cultural assumptions.

Research shows that cross-cultural differences surface even in the simplest of negotiation games, for example, the Dictator Game (Henrich et al. 2006). For such a simple game, of course, drawing real-world analogies is a challenge. On the other hand, for negotiation situations closer to real life, comparability across cultures can be problematic, since each situation takes its meaning in the specific cultural context in which it occurs. In this article we seek the middle ground between simplicity and realism, by taking a fairly iconic situation of trade with a hidden quality attribute: the trade of a second-hand car. We aim to compare actual negotiation behaviours with economic rationality and to find interpretable cross-cultural differences. For the hypothesis that economic behaviour depends on culture, we coin the term 'relational rationality'. This means that actions are rational from the perspective of the social world in which the actor lives, with interpersonal relationships weighing heavily. Economic rationality, in this view, would just be one of many possible ways of being relationally rational, the assumption being that relations do not matter. In this article we shall use 'economic rationality' in the usual sense, and 'relational rationality' when the social world is included.

Empirical research to the influence of culture inherently requires subjects from different countries. Gathering subjects in one location for an experiment is difficult. Therefore, we decided to develop a simple online game that makes relationship, and in particular differences in social status, salient: the Lemon Car Game (Hofstede et al. 2009a). The experimental device allows participants to choose a hypothetical social status in the game. Further, participants are assigned hypothetical personal relationships with the other negotiators. These choices served to engage the participants' imagination about the context of the negotiation, and make the game less abstract. As of the end of 2016, when we began the analysis reported here, the game had been played by over 800 participants from more than 70 countries.

Analysis of the results from the game finds differences in negotiation behaviour depending on cultural origin, social status (in the game), and personal relationship with the negotiation partner (in the game). Second, we find that the link between stated intentions and actual negotiation behaviour is only meaningful within a specific cultural frame of reference. Third, we find that at country level, the cultural dimension of Long-Term Orientation (Hofstede et al. 2010a, b) correlates with cheating one's negotiation partner in the game. Fourth, our findings show that to make sense of the players' actions during negotiation, economic rationality falls 
short. We conclude that relational rationality drives the players in the game, with interpersonal relationships weighing heavily.

Note that our game does not internally contain cross-cultural negotiations; but participants from different cultures played it, and we compare their negotiation behaviours.

In the following sections we first provide background and introduce the Lemon Car Game. Next we present our methodology. Following, we analyse the results obtained to date using multiple analysis lenses. These lenses include both economic and relational rationality, and the latter both at individual and at cultural level. We discuss the implications of the results and the experimental limitations. We conclude with directions that flow from our work.

\section{Background and Related Work into Cultural Differences}

This section gives background, highlights the most salient literature on culture and negotiation, and introduces the Lemon Car Game.

\subsection{Culture in a Trade Game}

We adopt the well-known cultural dimensions model of Hofstede (2001) that sees culture as 'software of the mind' that pre-programs members of societies in shared ways. In its current form (Hofstede et al. 2010a, b), the model consists of six bipolar dimensions of culture, each of which is a trait of a society. These are power distance, individualism, masculinity, uncertainty avoidance, long-term orientation, and indulgence. All of the dimensions can be correlated with cultural differences in negotiation (Verwaart 2011; Hofstede et al. 2012).

It is known from psychological experiments that framing can have large effects (Smith et al. 2006). We also knew, from playing the game The Takeover Trio (Bots and Hofstede 2004) online, that games played over technological devices can underestimate relational effects. Therefore we wished to bring some relational framing to our game when translating the face-to-face version (Hofstede et al. 2009a) into an electronic version. We concentrated on two dimensions: individualism, the degree of independence versus group-based interdependence in a society, and power distance, the extent to which the lower ranking individuals of a society "accept and expect that power is distributed unequally" (Hofstede 2001). Participants had to select a personal relationship with the other party, and a social status.

Individualism distinguishes the 'West' from the rest of the world, with the former at the individualistic extreme of the scale. This means expression of individual choices and opinions is valued. On the collectivistic end of the scale are many other countries, in particular Southeast Asian and Central American. In these societies, behaviours follow patterns prescribed by social role in fixed in-groups.

Power distance ranges between small power distance, in egalitarian societies (e.g., Anglo, Germanic and Scandinavian cultures), to large power distance, in hierarchical societies (e.g., the majority of cultures in the world). People in societies 
with a large power distance are more likely to conform to a hierarchy where "everybody has a place and which needs no further justification", whereas those in societies with a small power distance are more likely to try to distribute power equally.

Hofstede et al. (2010a, p. 400) argue the importance of culture in negotiation. They say that individualism affects the need for a prior relationship between wouldbe negotiators. As for power distance, they argue that it affects the influence of the negotiators' status on negotiation process and outcome. These authors hypothesized that status will matter little to negotiators from egalitarian cultures, who will negotiate based on other considerations, but that it will matter very much to participants from authoritarian cultures. The latter will tend not to dare oppose negotiators of higher social status, and will impose their own terms on negotiators of lower status.

Note that individualism and power distance are society-level cultural dimensions, hence shared ways of thinking, not attributes of individuals. The difference in social status between two individuals may impact their relative power in bilateral negotiation, but negotiation power itself is a different topic (Wong and Howard 2017).

Adair et al. (2004) provide empirical evidence for the relevance of power distance for negotiation processes. Subsequently, to simulate the effects of cultural differences in trade processes, Hofstede et al. (2009a, b) developed an agent-based model of differences in power distance, based on the work of Hofstede (2001). Their hypotheses imply significant differences between hierarchical and egalitarian societies, with respect to (1) the frequencies of making counter-proposals and breaking off negotiations, (2) utilities for which parties accept proposals, and (3) expected and realised truthfulness of deliveries. The Lemon Car Game offers an environment to test such hypotheses empirically.

\subsection{The Lemon Car Game}

The Lemon Car Game was introduced in Hofstede et al. (2009a). The game hinges upon three aspects: (1) the economic value of the transactional article, a secondhand car, being known within reasonable limits-but the car potentially suffers from a hidden quality defect, (2) the relative social status of the negotiators, and (3) the possible personal relationship between the negotiators.

In the game, two cars are available to the seller; one has sound quality, a 'jewel' (or 'peach' in Akerlof's (1970) terminology) whereas the other looks identical but has a hidden defect, the 'lemon'. The jewel is worth approximately $\$ 2800-\$ 3000$ while the lemon is worth approximately $\$ 2300-\$ 2500$. The sale could concern either car and the buyer's only way to find out whether he is purchasing the lemon is to have an independent quality check performed. Such a quality check costs $\$ 300$. The buyer has to decide whether to trust the seller. The seller has to decide whether or not to exploit the buyer, by pretending the lemon car is a jewel. The players are informed about the above cost structure, the relative social status of the negotiating parties, and their personal relationship (if any). However, the buyer is not informed about the actual value of the lemon. Buyer and seller have to negotiate the price, whether and when to have a third-party check for defects, and who pays the third party check if so. Either player can break off negotiation at any point. 
The Lemon Car Game is related to the rich line of literature starting with Akerlof's seminal study (1970) of the second-hand car market. An example of empirical research into the existence and nature of such markets is Hoffer and Pratt (1987). Our work differs from that line of research in its aim, which is to empirically study cross-cultural negotiation, not second-hand car markets; in our work the lemon car is just the transactional article in the game and the game is just the experimental device. The setup of the Lemon Car Game differs from Akerlof's (1970) game-theoretical analysis in three ways: (1) buyer and seller negotiate over the inspection (or not) and who pays for it, as well as the price, (2) the game exploits the social statuses of the negotiators, and (3) the game assigns an explicit personal relationship between the negotiators.

The incentive structure of the Lemon Car Game is as follows: if both parties cooperate, the sale will be truthful and the pair of traders will spare the cost of checking. If the seller expects to be distrusted, she could either sell the lemon (as Akerlof), or have a quality check performed up front or offer to pay for one. If the buyer distrusts the seller, the result depends on whether the buyer wants to have the jewel or does not care: in the former case the check will be needed, but in the latter the lemon might be sold. If the check is required, it can be negotiated who pays for it and what happens in case a supposed jewel turns out to be a lemon.

Each player of the game selects the role of buyer or seller. In addition to the above scenario, players select a hypothetical status in society (quartile) and are given a hypothetical relationship to the other player (ranging from stranger to family member). The differences in status in society indicate (dyadic) power distance. The game is constructed such that the expectation of trust is important, alongside a preference for high quality or low price. Hence, prior to the game, players are asked four value statements. For sellers, these up-front, before-game questions are (analogously for buyers):

- BestPrice: "How important is it to you to fetch the best price?"

- GetRid: "How important is it to you to get rid of the lemon?"

- BeFair: "How important is it to you to be fair to the buyer?"

- Depends: "How much does it depend on who the buyer is?"

The online game (Fig. 1) is hosted at: ii.tudelft.nl/TACT/index.php/Lemon_Car_ Game. Having chosen the role of buyer or seller, the player is provided with the scenario, and then is confronted with hypothetical moves (i.e., proposals) by his opponent. To each of the opponent's moves the player can indicate what he would reply (e.g., accept, counter-offer,...), and why he would reply in that way. A number of demographics are collected from the players, as a proxy for personality and culture data, and a debriefing questionnaire is administered at the conclusion. Figure 6 in the Appendix overviews the game's flow in the online modality. 


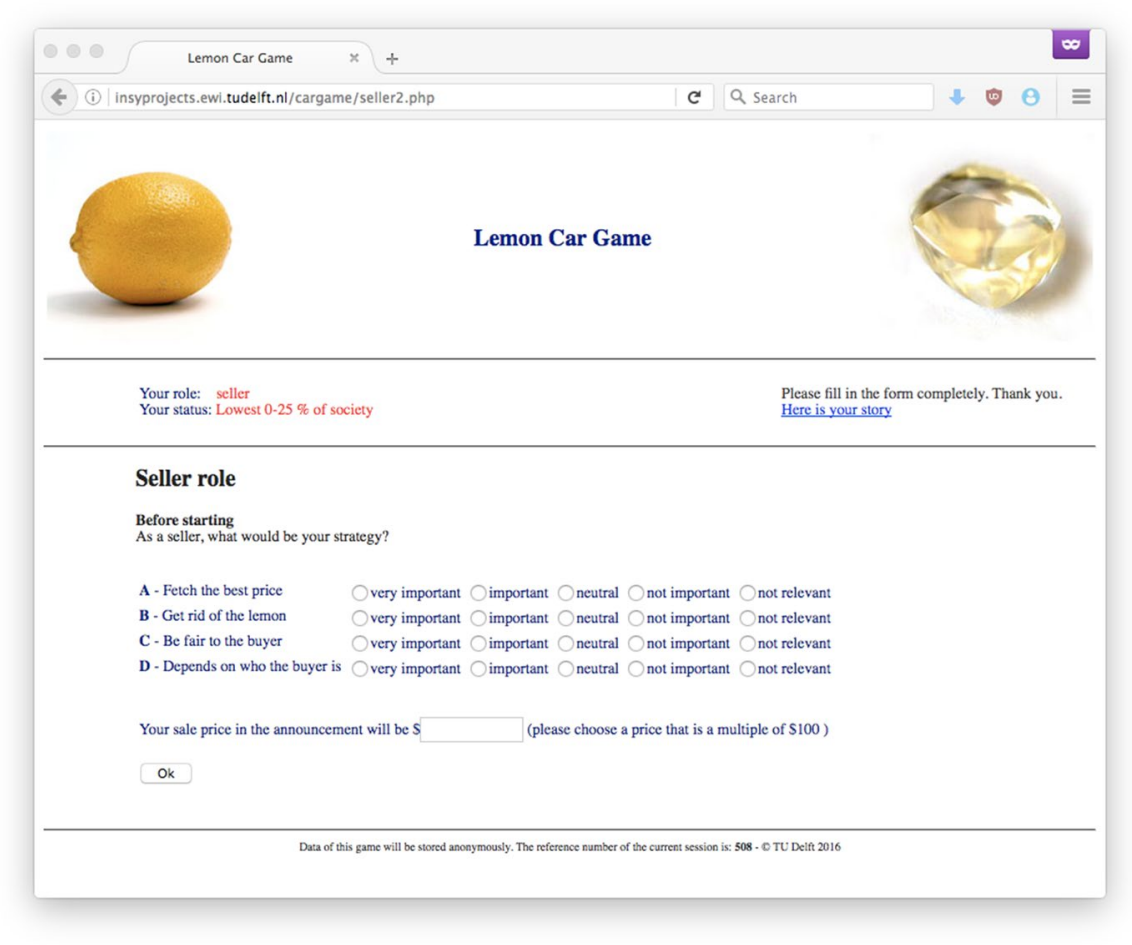

Fig. 1 One screen of the Lemon Car Game, online modality

\section{Methodology}

Using simulation games to investigate human behaviour in a business or social context is now recognized for its value (Hofstede et al. 2010a, b). Hofstede and Meijer (2007) discuss collecting empirical data with games, concluding that very large numbers of respondents would be needed to reach statistically reliable results. As described in the previous section, data collection for our work was accomplished by using a simple online game. In line with the hypothesis that rationality is modified by the culture and relational standing of people when they interact, we chose to capture two aspects in the game: the relationship between the players, and the players' difference in societal status.

Constructed research studies place people in an artificial environment. In contrast, allowing people to participate in socio-psychological studies while staying in their own habitat enhances the naturalness of their reactions, and removes some of the main barriers for participating in research studies (Paolacci et al. 2010): no pre-scheduled time is needed, nor travel, nor lengthy instructions. Accordingly, the Lemon Car Game takes 5 to 10 min to play, e.g., as a break in the normal daily routine, and it can be played from any web-enabled device. The broader lab/online/ field comparison is discussed for instance by Barry (2008), Karagözoğlu and Urhan 
(2017), Paolacci et al. (2010). Being simulations, however, online games nonetheless share the limitation of in-person simulations in the extent to which participants can identify with their role in the game.

The use of the Lemon Car Game is in line with the use of simple games in the social psychology and experimental economics literature, such as the ultimatum and dictator games (see Engel 2011; Karagözoğlu and Urhan 2017). The difference is that, while these games provide insights into behaviour, they do not give insight into the context and assumption of the players. We seek the middle ground between simplicity and realism, by taking a fairly iconic situation of trade with a hidden quality attribute.

Before building the online version we created a person-to-person version of the game. This version was tested at the ISAGA 2008 conference as reported in Hofstede et al. (2009a). We conducted a pilot test of the online game before opening the game to everyone. We chose to create the game in English. This choice avoids the overhead of translation and suggests a certain minimum level of education in most countries. For future research in which a broader population is to be attracted, the simplicity of the game nonetheless makes it easy to make translations of the game for other languages.

Progressing from the development of the game (2008) until having the results reported here took some years, for a combination of reasons. Importantly among these, we wanted people of diverse backgrounds to play the game from their natural settings, and therefore chose not to use, e.g., Amazon Turk to recruit and pay people to participate (Paolacci et al. 2010; Teschner and Gimpel 2018). We wrestled with how, when, and where to advertise the game. While it would be relatively easy to recruit participants (i.e., university students) from the institutions of the investigators, instead we were interested in having participants from a wide spectrum of countries, diverse in terms of cultural dimensions. For the most part, rather than actively recruiting we decided to announce the game on the website www.geerthofstede.com and allow participants to opt to play.

Having decided against using paid participants, in 2008-09 and again in 2013-14 we wrote to our network of colleagues to ask them to socialize the game by sharing the link to it. We obtained sizeable responses from Iran and Lebanon from dedicated recruitment efforts made in those countries, and a slow but steady stream of participants from other countries. In 2016 we shared a flyer at the ECAI, ESSA and Artificial Economics conferences, which resulted in a burst of new participants.

\subsection{Hypotheses}

Our overall hypothesis is that relational rationality will work in different ways across cultures, and that this will modify the negotiation behaviours and outcomes of participants. So we assume that relational rationality modifies economic rationality, and that it has components that are shared within a culture. As a consequence, we expect that comparisons of cultures will allow to reveal differences in game behaviours 
more clearly than comparisons across all individuals. We also assume that statements made by participant may not mean the same thing across cultures.

Specifically we hypothesize that:

H1 To the extent that participants come from a culture of larger power distance, they will be more sensitive in their negotiation behaviour to their assumed social status in the game.

H2 The relationship between what participants say and what they do will be clearer in a comparison across countries than across individuals.

In H2, 'what they say' refers to the answers participants give to the questions in Fig. 1; 'what they do' refers to the game actions of participants such as bidding prices, selling the lemon or the jewel, etc.

\section{Results and Analysis}

In this section we report and analyse results from the Lemon Car Game in the period 2009-2016. Our analysis is structured into the following subsections. First we present demographics and variables of our study (Sect. 4.1). Second, we compute utilities from the game outcomes, and perform analyses accounting for participant rationality in the economic sense (Sect. 4.2). This allows us to compare the participants' observed behaviour against the theoretical utility-maximizing rational behaviour in the case of sellers. Third, we perform three analyses accounting for participant rationality in the relational sense (Sect. 4.3). This analysis consists of an individual-level pan-cultural analysis considering participants from all countries, in Sect. 4.3.1; a cross-cultural ecological analysis considering participants split by cultural grouping (country of origin), in Sect. 4.3.2; and lastly, in Sect. 4.3.3, a qualitative analysis of the stated motivations of participants, to better understand the rationale for their observed behaviours in the game.

\subsection{Demographics and Variables}

After removal of incomplete participations, we obtained 806 completed instances of the game. In their self-reported demographics, participants reported 73 countries of origin. The majority, $72 \%$, of participants opted to take the role of buyer in the game. Of the participants, $42 \%$ were female; the most common age bracket was 26-35 years; the mean number of years of full-time education was 15.9 , i.e., at least some university education. Approximately one-third of participants reported their job as professional but not managerial, and another third reported they were fulltime education or had no current employment. The most common reported actual status in society was the third quartile: $56 \%$ of participants. Table 1 shows the distribution of participants by country of origin and by country of current residence. 
Table 1 Participants' cultural backgrounds

\begin{tabular}{lclc}
\hline Country of origin & Respondents & Country of living & Respondents \\
\hline United States & $122(15.1 \%)$ & Lebanon & $127(15.8 \%)$ \\
Iran & $103(12.8 \%)$ & United States & $118(14.6 \%)$ \\
Lebanon & $86(10.7 \%)$ & Iran & $101(12.5 \%)$ \\
Netherlands & $81(10.0 \%)$ & Netherlands & $93(11.5 \%)$ \\
Germany & $35(4.3 \%)$ & United Kingdom & $51(6.3 \%)$ \\
United Kingdom & $35(4.3 \%)$ & Germany & $33(4.1 \%)$ \\
China & $29(3.6 \%)$ & Australia & $31(3.8 \%)$ \\
Slav & $26(3.2 \%)$ & Scandinavia & $24(3.0 \%)$ \\
India & $25(3.1 \%)$ & India & $17(2.1 \%)$ \\
Canada & $22(2.7 \%)$ & Austria & $15(1.9 \%)$ \\
\hline
\end{tabular}

Table 2 Variables for analysis of data

\begin{tabular}{|c|c|c|c|c|}
\hline Variable & Type & Buyers? & Sellers? & Meaning \\
\hline BestPrice & Statement & Yes & Yes & $\begin{array}{l}\text { I want to fetch the best price (1: important, } \ldots, 5 \text { : } \\
\text { unimportant) }\end{array}$ \\
\hline GetRid & Statement & Yes & Yes & I want to avoid/get rid of the lemon \\
\hline BeFair & Statement & Yes & Yes & I want to be fair to the buyer/seller \\
\hline Depends & Statement & Yes & Yes & $\begin{array}{l}\text { My behaviour depends on what happens during the } \\
\text { negotiation }\end{array}$ \\
\hline Honest & Statement & Yes & No & I expect the seller to be honest \\
\hline FirstBid & Action & No & Yes & Value of the opening selling bid \\
\hline StatusNo & Choice & Yes & Yes & $\begin{array}{l}\text { Value of my chosen social status (1: lowest, ..., } 4 \text { : } \\
\text { highest) }\end{array}$ \\
\hline SelTrue & Action & No & Yes & $\begin{array}{l}\text { I sold the jewel under at least one branch of the nego- } \\
\text { tiation tree }\end{array}$ \\
\hline SelCheat & Action & No & Yes & $\begin{array}{l}\text { I sold the lemon under at least one branch of the } \\
\text { negotiation tree }\end{array}$ \\
\hline SelCounter & Action & No & Yes & $\begin{array}{l}\text { I made a counter-offer in at least one branch of the } \\
\text { negotiation tree }\end{array}$ \\
\hline SelBreak & Action & No & Yes & $\begin{array}{l}\text { I broke off negotiations in at least one branch of the } \\
\text { negotiation tree }\end{array}$ \\
\hline
\end{tabular}

A number of variables were collected. These include the before-game statements and the in-game actions summarized in Table 2. Some variables were collected for all participants, other for buyers or sellers as relevant. In addition, participants were asked ex post questions in the debriefing questionnaire.

\subsection{Economic Rationality Analysis}

The overall hypothesis, that relational rationality will work in different ways across cultures, implies that average game outcomes in terms of purely financial utilities will be different across countries. To test this hypothesis, we computed financial utilities for 
the game instances that resulted in a deal and analyzed the differences between countries with respect to average financial utilities for buyers and sellers. This subsection first explains the computation of utilities and then presents results from the analysis for buyers and sellers respectively.

We assume that the seller's and buyer's valuations are reflected in the actual transaction price, and that they would not only take financial or economic value into account, but also relational aspects of the deal. We use financial utility computations to compare the agreed price with the actual market value, as an indicator of relational motivations. Based on the scenario descriptions, the seller's financial utility $U s$ can be computed as the extent to which the agreed price exceeds the car's minimal market value:

$$
\begin{aligned}
& U_{s}=p-v l-t \quad \text { if seller pays for inspection with a resolutive condition, } \\
& U_{s}=p-v l \quad \text { if seller agrees on a resolutive condition and buyer pays for inspection, } \\
& U_{s}=p-v l+r \quad \text { if seller can deliver the lemon, } \\
& U_{s}=p-v l \quad \text { otherwise, }
\end{aligned}
$$

where $p$ denotes the negotiated price, $v l$ the lower bound of the jewel car's value, $t$ the transaction cost (i.e., the cost of third party testing), and $r$ the actual cost of repair for the lemon. In these equations the lower bound of the car's market value is used to compute the seller's utility, since the seller is assumed to easily find alternative buyers for this price.

The above utility function is used in the analysis of the outcomes of the game, below, to determine deviations from what can be considered the financially-rational outcome. For that purpose, we select as observations those proposals for which a player indicated agreement (complete acceptance, or acceptance to some extent) with the opponent's proposal (see Fig. 6). For all such observations, the minimal utility Umin that the player stated to agree upon is determined, as an indicator for the extent to which the player is willing to make concessions. We perform the utility analysis for sellers, since for buyers an upper bound on the jewel value is needed.

\subsubsection{Sellers' Utility Analysis}

In the game, potential seller can make an opening bid and then are presented with the following buyer's responses:

- agrees on the condition that you pay the inspection cost of $\$ 300$ and no defects are found;

- makes a counter-bid of $\$ 3000$, and demands that you also pay for the inspection;

- makes a counter-bid of \$2800, and does not demand inspection;

- makes a counter-bid of $\$ 2500$, and does not demand inspection.

The seller then can either accept and deliver the jewel, accept and deliver the lemon, make a counter-offer, or break off. For the cases where a seller accepted one or more of the options, the minimal utility can be calculated, for which the seller would accept. If players agreed for negative financial utilities, or agreed only for 
Table 3 Number of seller role observations (with asking price up to $\$ 3500$ ) and mean minimal utility

Fig. 2 Box plot of minimal acceptable seller' utilities (ANOVA)

\begin{tabular}{lll}
\hline Country of origin & $\begin{array}{l}\text { N (sellers, per } \\
\text { country) }\end{array}$ & $\begin{array}{l}\text { Mean minimal } \\
\text { utility }(U \mathrm{~min})\end{array}$ \\
\hline United States & 25 & -268 \\
Iran & 33 & -172 \\
Lebanon & 14 & -79 \\
Netherlands & 14 & -50 \\
United Kingdom & 12 & -25 \\
\hline
\end{tabular}

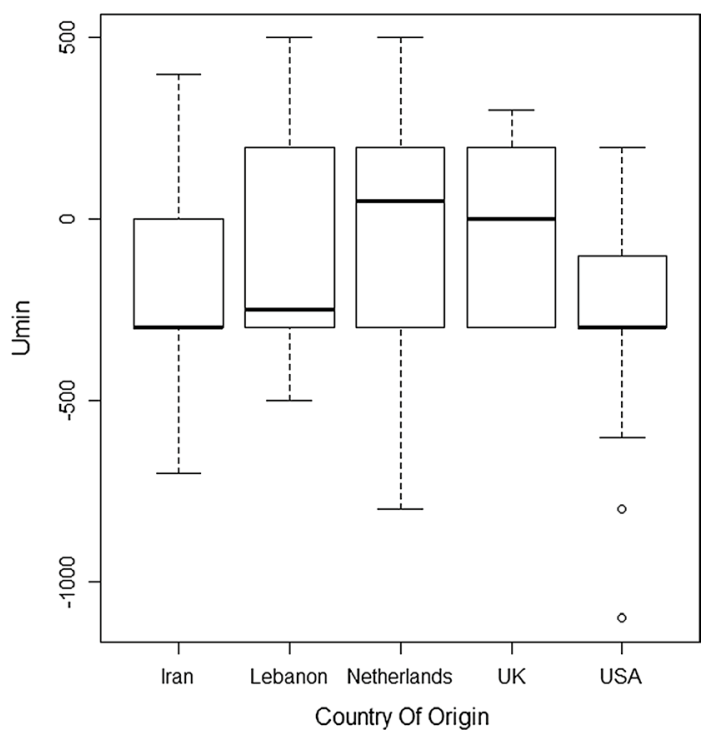

relatively high utilities, this indicates that other than purely financial factor played a role. Differences in average utilities between countries may indicate differences in the presence of such factors. The analysis indicates the presence of such factors.

For the purpose of the analysis we selected responses with an opening bid of $\$ 3500$ or less to obtain realistic outcomes for the sellers' minimal acceptable utilities. Table 3 presents average minimal utilities for which sellers would accept the buyers' offers, for countries from which at least $n=10$ observations are available after selection. The box plot in Fig. 2 suggests differences between minimal acceptable utilities across countries, but the relation is barely significant $(p=0.060)$.

In summary, the utility-based analysis indicates modest differences according to participants' culture as captured by country of origin. We next turn from an economic analysis to a relational analysis.

\subsection{Relational Rationality Analysis}

Humans are characterized by different levels of uniqueness: some prominent levels are the individual, the society, and all of humanity. One has to be clear about 
the target level of analysis. This level could differ from the level at which data are collected. For the Lemon Car Game we collect data at the level of the individual and analyse them at three levels: entire respondent population, (nation-level) cultural groups, and individual statements. We will analyse relational rationality in terms of all three of these levels in this section. Following Hofstede (1995) we call the first of these levels 'pancultural analysis': each individual counts as one observation, and there are no subgroups. We call the country-level analysis 'ecological analysis': each country counts as one observation, regardless of the number of participants from that country.

Perhaps one example can clarify why this difference matters. Lincoln and Zeitz (1980) describe a study among 500 employees of 20 social service agencies in the United States. The study concerned the relationship between professional qualification and supervisory duties. At the individual level the relationship was positive: more diplomas, more likely to supervise. In an ecological analysis at the level of the social service agency, however, the relationship was negative: the higher proportion of highly-educated people, the less supervision needed and fewer people involved in supervision.

\subsubsection{Pan-Cultural Analysis of Entire Population}

In the first of our levels of relational rationality analysis, we performed an individual-level analysis of the whole data set in order to determine individual-level effects. We treated buyers and sellers separately, since different variables are available for the two roles.

We attempted several pancultural factor analyses for the buyers. For these participants, however, we only have statements and no data on game actions, as seen in Table 2. The resulting factor matrix, whether we used fewer or more countries, tended to be rather spherical and yield trivial factor structures. We can conclude that across cultures the buyers' statements on intentions were not very meaningful. Buyers' free-form textual comments yield more insight, as Sect. 4.3.3 reports.

The number of observations obtained so far is insufficient to find significant relations of other variables with utility differences between countries. However, some relation with trust is indicated. For instance, there is a highly significant relation ( $p=0.000002$, Kruskal-Wallis test) between country of origin and the answer to the question “Suppose the seller's opening bid was \$3200. What do you think (s)he is trying to sell? (1: jewel; 5: lemon)". In particular, significant differences $(p<0.01)$ according to Dunn's test for multiple comparisons with Holm adjustment are found between Iran and the other countries, except India and China (see Fig. 3).

We also conducted pancultural analysis for sellers. After correction for multiple correlations, no significant conclusions were observed at the $5 \%$ significance level.

\subsubsection{Cross-Cultural Ecological Analysis}

In the second of our levels of relational rationality analysis, we grouped the respondents by culture. The aim is to see whether we could tease out the cross-cultural 


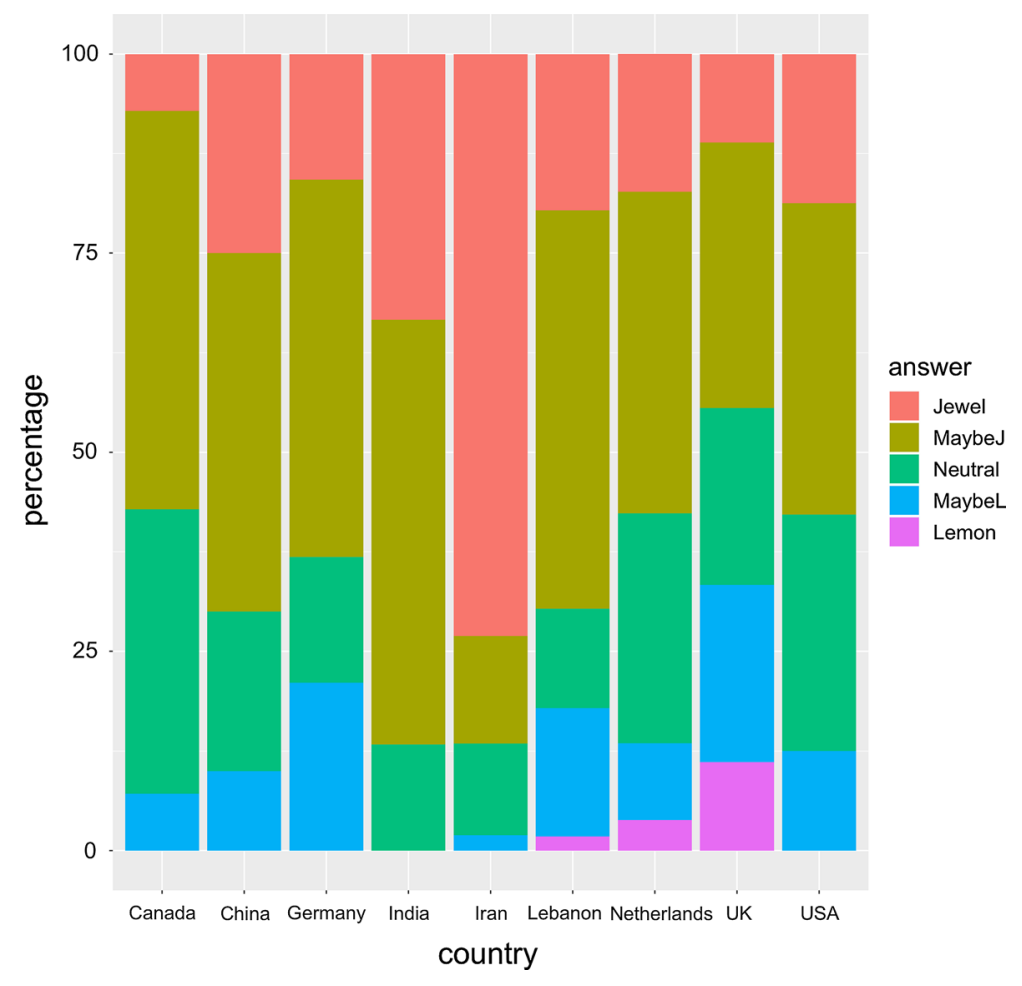

Fig. 3 Percentage of respondents stating that they believe that a jewel car or a lemon car will be delivered after a bid of $\$ 3200$, by country

differences that might have been obscured by the aggregating together of all respondents as was done in the above pan-cultural analysis.

Two comments about methodology are warranted. First, we recognise that economic activities such as negotiating a deal are usually analysed at the individual level. However, we suspected that some patterns may only reveal themselves in a culturelevel analysis. Such an analysis is called ecological (Hofstede 1995), since it aggregates individuals at the level of the cultural group before doing any statistics. In this article we employ both the individual-level (last subsection) and the ecological analysis (this subsection). We expect to find different patterns, as for instance argued in a methodological work on levels of analysis in social psychology (Hofstede 1995).

Second, it is worth noting that in an ecological analysis, some standard assumptions about statistics can be altered. For instance, an ecological factor analysis will have fewer cases than a regular one, since these cases are themselves aggregates of many respondents: hence in such a factor analysis, a lower case/ factor ratio is acceptable than would normally hold. Also, each country is seen as one case with equal weight, regardless of the number of respondents that were averaged to obtain the country-level data. 


\section{Buyers}

Given the total number of participants who took the role of buyer $(n=474)$, if we limited ourselves to the 13 countries with $n \geq 10$, we lost variety in our country sample. Hence we traded a lower limit of respondents per country for a higher number of countries, in the cross-cultural analysis of buyers. We took countries with at least $n=5$ respondents, giving a sample of 26 countries. To obtain more clusters, we grouped together some countries that have similar cultural characteristics according to Hofstede et al. (2010a). For instance, Russia, Serbia/ Montenegro, and Bulgaria we grouped into 'Slav', and Spain and Portugal into 'Iberia', taking the mean of the culture scores of these countries as the culture score for each dimension. We did this only for countries with very similar culture scores. We refer both to ungrouped countries (e.g., United States) and grouped countries (e.g., Slav) as simply 'countries' in the below. Table 4 shows the set of respondents.

For buyers we did not collect the kind of negotiation behaviour variables as we did for sellers. Hence for the buyers we did not create any extra columns, but worked with the four pre-game statements (BestPrice, GetRid, Depends and BeFair), the expectation of honesty of the other party, and the self-reported status in society. We performed a factor analysis using Principal Component Analysis. The scree plot is shown in Fig. 4. We extracted three factors, as shown in Table 5.

We interpreted the factors as follows:

- Result. The outcome is the main factor (30\% of variance). Note that since BestPrice_mean is reverse-coded, a negative value means that, indeed, the buyer wants to go for the best price. This factor includes expecting the seller to be honest, aiming for the best price, and not aiming to be fair. Statements by the buyers confirm that their main worry is whether the seller will be honest. It is connected with a desire to get the best deal. Fairness seems not to carry such a clear connotation.

- Face (25\%). This contains high self-selected status, associated with not wanting to avoid getting the lemon, with a lesser loading for caring about fairness. Apparently, status-seeking as per the self-selected status in society correlates with lower importance of price, but higher importance of driving a jewel car. Worrying about price could be beneath such participants, but they want to be seen owning a perfect car.

- Flexibility (20\%). This is a motivation to negotiate, and to respond to whatever the seller does, while being concerned about the price.

We were unable to find relationship with culture for this dataset. This might be because we did not have actual negation behaviours for the buyers.

\section{Sellers}

We performed a factor analysis on country averages of the same variables as before. Initially we considered only countries with at least $n=10$ seller respondents, but with only six countries the resulting matrix was inconclusive. We then considered $n=4$, in order to gain pattern by including these four such countries. This 


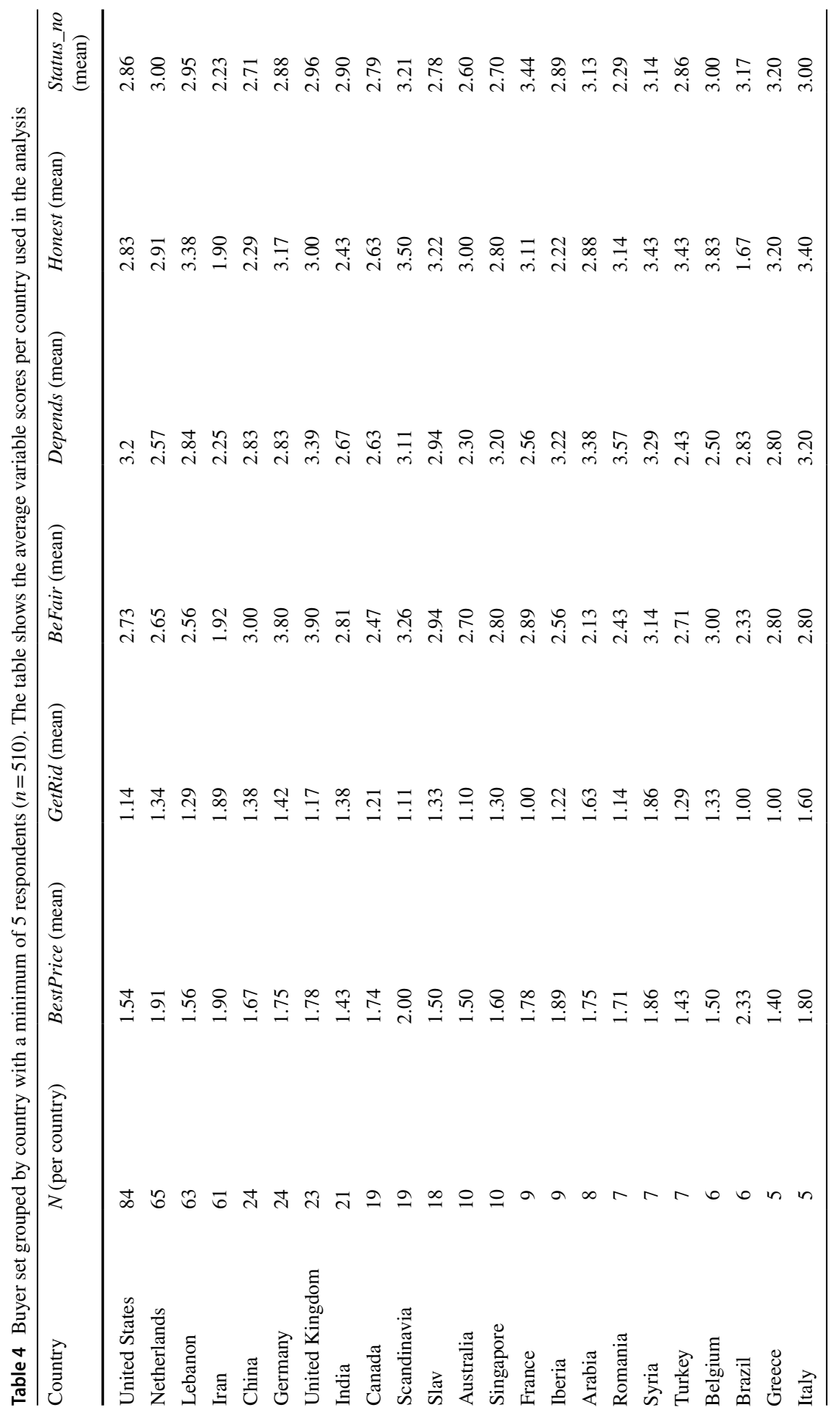




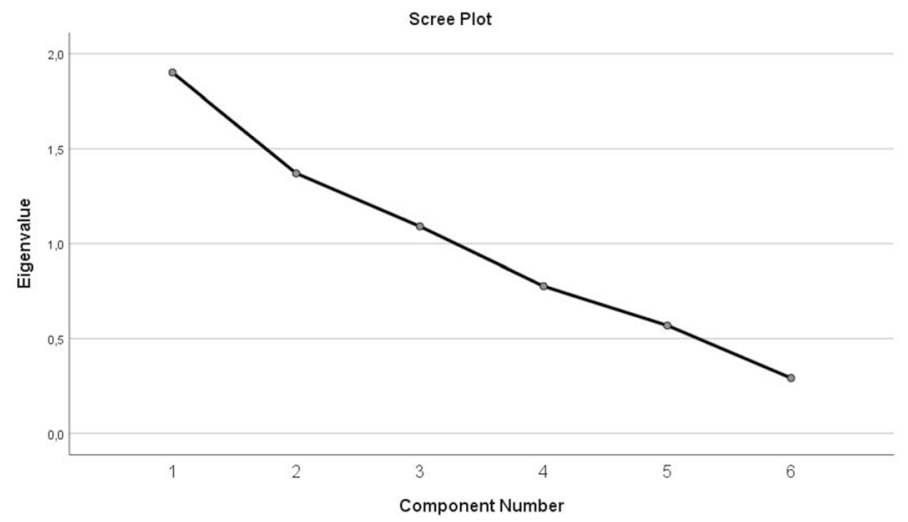

Fig. 4 Scree plot for buyers, cross-cultural analysis ( $n=23$, based on 510 respondents)

Table 5 Component matrix of cross-cultural buyer factor analysis after varimax rotation

\begin{tabular}{lccc}
\hline & \multicolumn{2}{l}{ Component } & \\
\cline { 2 - 4 } & 1 & 2 & 3 \\
\hline BestPrice_mean & -.770 & .186 &. $\mathbf{4 6 8}$ \\
GetRid_mean & .043 & -.763 & .352 \\
BeFair_mean & .635 & .496 & .254 \\
Depends_mean & .043 & .001 & .847 \\
Honest_mean & $\mathbf{. 8 9 6}$ & .095 & .145 \\
Status_no_mean & .116 & $\mathbf{. 7 8 0}$ & .291 \\
\hline
\end{tabular}

Extraction method: principal component analysis. Rotation method: varimax with Kaiser normalization. Rotation converged in 6 iterations. Loadings above 0.4 are in boldface. Items in italics are reverse coded

yielded the 14 countries of Tables 6 and 7. Although this number is quite low, it does capture central tendency among the respondents to a degree that allows analysis.

For sellers, we have four variables capturing negotiation behaviour, which we added as columns to the matrix. We performed an ecological factor analysis on the country averages of the variables. The scree plot had four components with eigenvalue $>1$, as seen in Fig. 5, but the fourth was hardly above 1, and did not yield a clearer factor structure, so we left it out. Hence, we extracted three components and carried out varimax rotation. This yielded the component matrix of Table 8 .

Note that now, in contrast to the individual level pan-cultural analysis, we see both statements and actions in each of the factors for the sellers. This indicates that the statements and actions are logically related per country. It seems to matter that now each basket has only respondents born in a single country. 


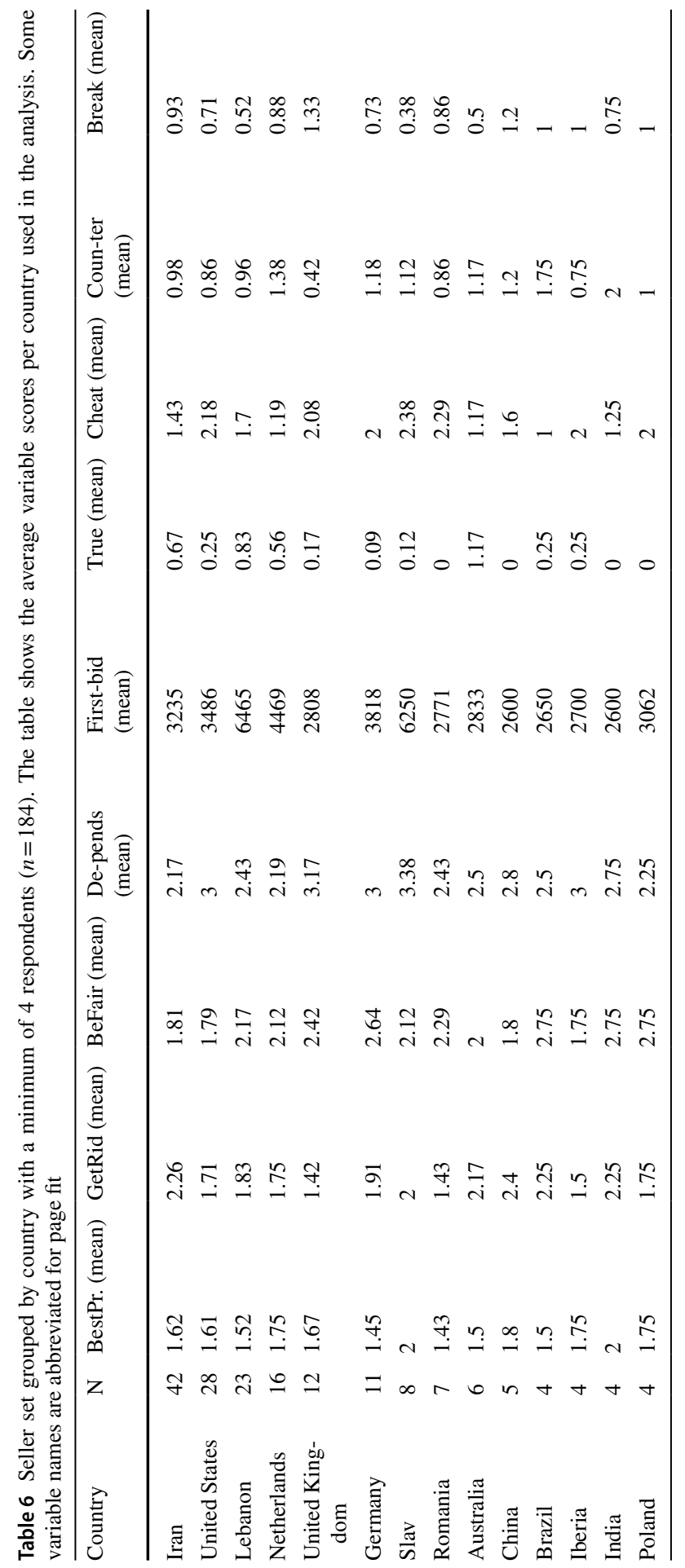


Table 7 Seller set grouped by country with a minimum of 4 respondents $(n=184)$. The table shows Hofstede culture dimension scores per country used in the analysis

\begin{tabular}{lccccccc}
\hline Country & $N$ & PDI & IDV & MAS & UAI & LTOW & IvR \\
\hline Iran & 42 & 58 & 41 & 43 & 59 & 14 & 40 \\
United States & 28 & 40 & 91 & 62 & 46 & 26 & 68 \\
Lebanon & 23 & 75 & 40 & 65 & 50 & 14 & 25 \\
Netherlands & 16 & 38 & 80 & 14 & 53 & 67 & 68 \\
United Kingdom & 12 & 35 & 89 & 66 & 35 & 51 & 69 \\
Germany & 11 & 35 & 67 & 66 & 65 & 83 & 40 \\
Slav & 8 & 90 & 35 & 40 & 90 & 80 & 20 \\
Romania & 7 & 90 & 30 & 42 & 90 & 52 & 20 \\
Australia & 6 & 38 & 90 & 61 & 51 & 21 & 71 \\
China & 5 & 80 & 20 & 66 & 30 & 87 & 24 \\
Brazil & 4 & 69 & 38 & 49 & 76 & 44 & 59 \\
Iberia & 4 & 60 & 40 & 35 & 90 & 38 & 39 \\
India & 4 & 77 & 48 & 56 & 40 & 51 & 26 \\
Poland & 4 & 68 & 60 & 64 & 93 & 38 & 29 \\
\hline
\end{tabular}

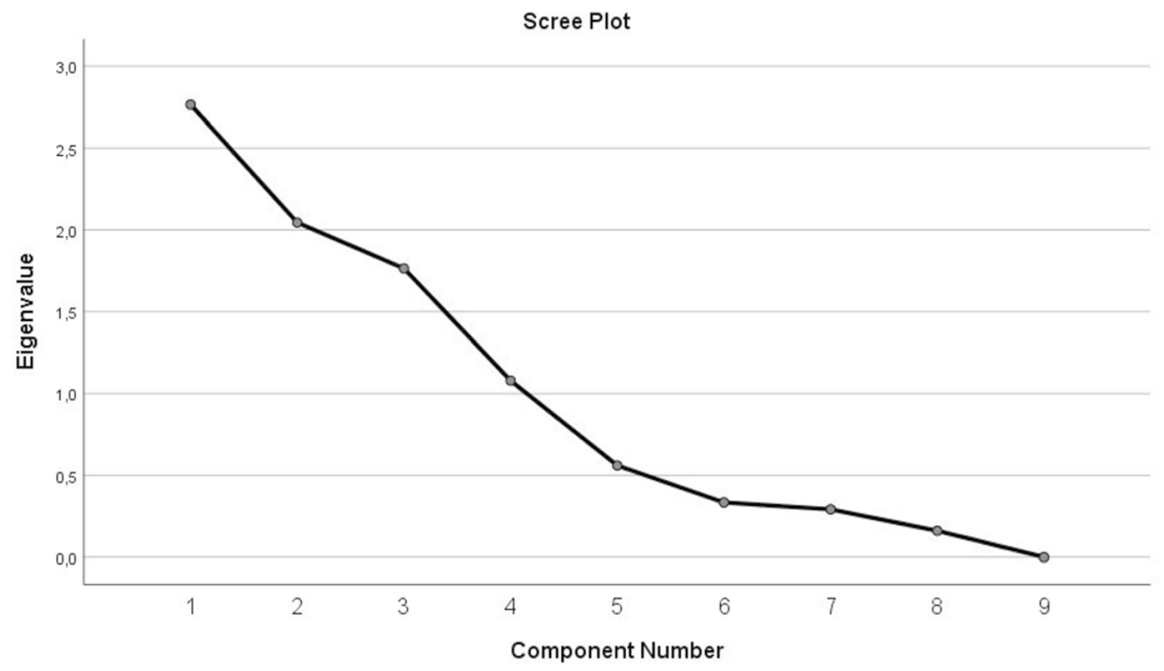

Fig. 5 Scree plot for sellers, cross-cultural analysis ( $n=14$ countries, based on 184 respondents)

- Trustworthiness (31.2\% of variance). Note that reverse-coded GetRid is positive, so no intention to sell the lemon. The factor is associated with not aiming to sell, and not actually selling, the lemon; and with making counter-offers. This points to moral commitment to the buyer.

- Disinterest (29\%). This is associated with not caring about the best price, not caring about the opponent's behaviour, and not selling the jewel. Its opposite would point to seriousness, flexibility, and interest. 
Table 8 Component matrix of cross-cultural seller factor analysis after varimax rotation

\begin{tabular}{|c|c|c|c|c|}
\hline & & \multicolumn{3}{|c|}{ Components } \\
\hline & & 1 & 2 & 3 \\
\hline \multirow{4}{*}{ Statements } & BestPrice_mean & .283 & .709 & .135 \\
\hline & GetRid_mean & .826 & -.049 & .133 \\
\hline & BeFair_mean & .379 & .283 & -.355 \\
\hline & Depends_mean & .343 & .716 & .168 \\
\hline \multirow{5}{*}{ Actions } & FirstBid_mean & -.106 & .124 & .852 \\
\hline & SelTrue_mean & .097 & -.788 & .507 \\
\hline & SelCheat_mean & -.805 & .494 & .115 \\
\hline & SelCounter_mean & .949 & -.136 & -.002 \\
\hline & SelBreak_mean & -.164 & -.003 & -.878 \\
\hline
\end{tabular}

Extraction method: principal component analysis. Rotation method: varimax with Kaiser normalization. Rotation converged in 5 iterations. Loadings above 0.4 are in boldface. Items in italics are statements and reverse coded, the others are actions

- Eagerness (26\%). This is associated with making a high first bid and not breaking off the negotiation. It bears little relations to the a priori statements.

Factor 1 seems to reflect the relationship the seller assumes with the buyer. It resembles factor 2 for the buyers. Factor 2 reflects a lack of interest in the relationship; its opposite would resemble factor 1 for the buyers. Factor 3 seems to reflect an interest in making money that is not stated, but is enacted.

Correlating factor scores with dimensions of culture in the ecological analysis did not yield any results for the buyers, but it does for the sellers. Factor 2 correlates with long-term orientation at $.632(p<.015)$. This means that short-term oriented culture is associated with a greater interest in the negotiation. This is what one would expect, since short-term orientation implies a greater commitment to the present compared to the future.

There is an important caveat to be made in the analysis of this subsection and the tentative interpretation. We are aware that the numbers of respondents per country do not warrant any strong conclusion about this factor structure.

\subsubsection{Motivational Analysis}

The analysis so far seems to suggest that the more we move from purely economic calculation to account for the social or cultural setting, the more patterns we see in the data. It makes sense, therefore, to go one step further and examine some of the free-form comments that players offered. Hence, we performed analysis at the level of individual statements. At the end of the game, participants were given opportunity to provide any optional comments they wished, as free-form text. Approximately $70 \%$ of participants chose to provide comments.

We show a small selection of representative comments and provide a larger range in the "Appendix". The comments suggest that the buyers' main objectives are to 


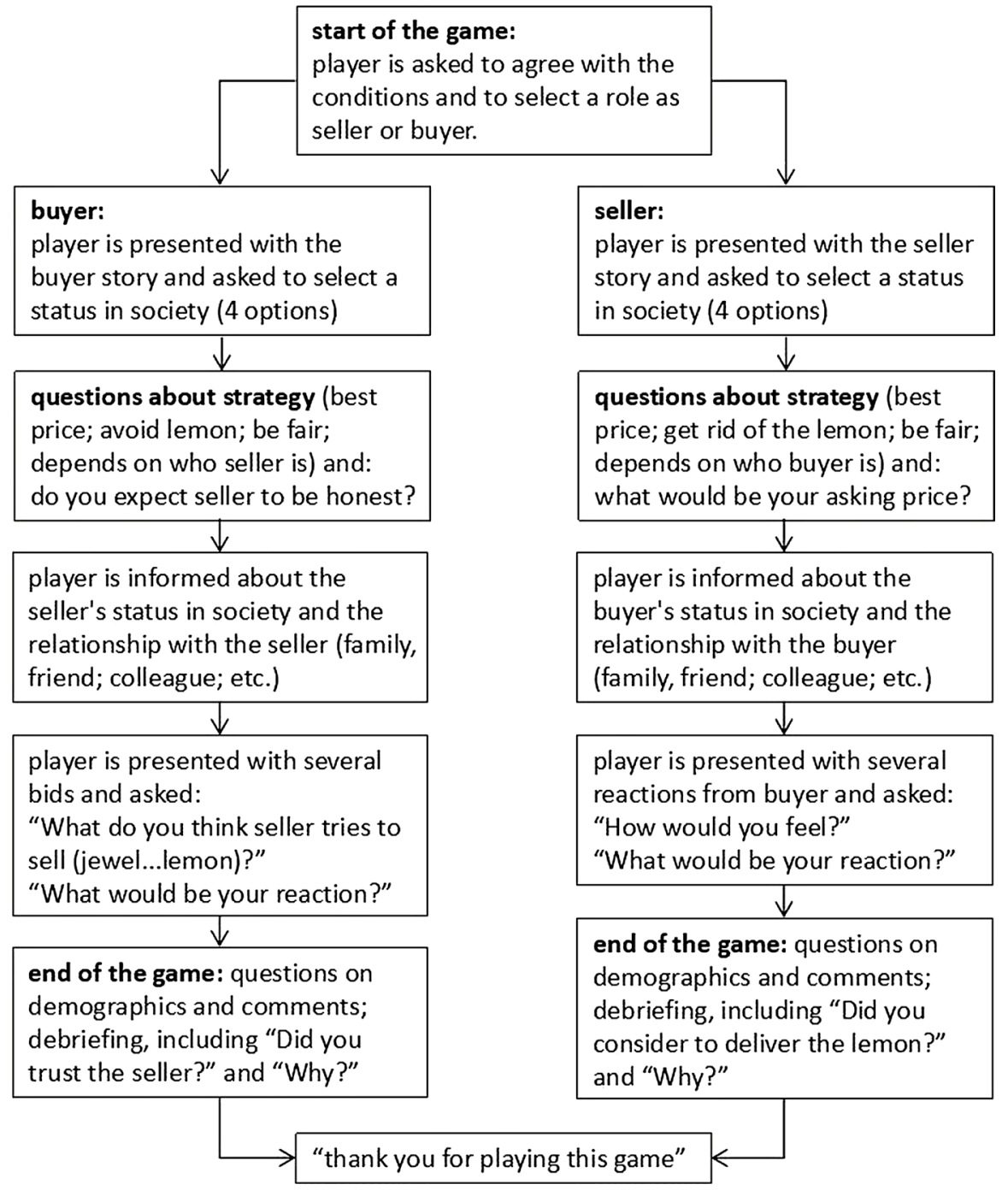

Fig. 6 Player flow through the Lemon Car Game, online modality

avoid the lemon and then to get the best price; the sellers' main objective seems to be getting the best price. So far, this is evidence of the salience of economic rationality. Other comments supplement this with relational reasons. Trust was commonly mentioned, as was evidence of trustworthiness (of the seller, or of the car if no evidence of trustworthiness is available), and buying/not buying from a seller with whom the buyer shares a close relationship. It is a robust finding that trust in strangers systematically differs between countries (Hofstede et al. 2010a), and this would obviously affect relational rationality when buying a second-hand car from strangers. 
Summarising, the free-form comments mention combinations of economic and social reasoning, and, as we elaborate below, that is precisely what relational rationality is about. In order to indicate the cultural background of the quoted respondents, we list their country-of-origin in brackets, and country-of-living, if different.

\section{Comments about objectives and relationships}

1. To minimize the risk of a bad outcome. (Netherlands)

2. Sellers would typically maximise their selling proposition in anticipation of bargaining downwards by buyers. (Singapore)

3. The seller always tries to give you incomplete if not false information in order to maximize her profits. (India)

4. Best price counts. (Germany)

5. I would also barter with the seller for the best price I could get. (Canada)

6. I wanted to know whether they were a private seller or it was their job. (United Kingdom)

7. Personally I would never buy a car from a relative as I don't want to have an emotional connection to neither price nor quality of the car. (Belgium, living in Germany)

8. It is always in someone's best interest to make a lemon pass off as a jewel. As I do not know the seller I have no basis of trust and so I do not take his statements at face value. (Netherlands, self-identified second generation immigrant)

9. I would prefer to find a control test of the car by a professional technician as an independent option not connected with any price as the real value of the car can shrink dramatically after test. Also I would like to know the nationality of the car-seller as in less developed countries the possibility to find an honest seller tends to zero while economically developed nations have built up rather trustful buyer-seller relationship. (Romania, living in Bangladesh)

10. I bought for my wife a second-hand car from her girlfriend emigrating to France. We knew her very well before. (Netherlands, living in Czech)

11. Because most of my relatives are liars and thieves. They know I am a trusting person and will try to take advantage of me. (United States)

12. My trust depends on our friendship. If we are very good friends I'll definitely trust him/her. However if the relationship is just so so I may not trust the statement. I'd like to know if he/she is honest and the reason why he/she wants to sell the car. (China, living in Netherlands)

\section{Comments about role identification}

13. I would need to have the car checked out before agreeing to buy the car. My husband works for a dealership. In real life I am looking to buy a car for my teenage son. (United States)

14. Used car sale may be common in western world. However this is not often encountered in China or India I think. (China, living in United States) 
15. Couldn't relate to the game because of age difference ( 22 vs. 42 ). I was made 20 years older. Could relate to the haggling part. (India)

16. In the game yes in reality no. If something is not ok with the car I'd either fix it or mention it. I would still aim to get the highest price for it. (Netherlands)

Three comments indicate that the participant found it hard to relate to the game, although the participants understood the game story and their role in it. A disconnect with participants' experience is probably unavoidable in such a simple online game; on the other hand, out of 806 responses, the number of such comments is very modest. More realism might not improve the situation. The comments indicate that if the players cannot relate to their role in the game it is because they relate too much to the particulars, see e.g., \#14 and \#15. If they can relate to it, they fill in not just intentions and aims of the other, but also relationships, see e.g., \#13, and relational causes and consequences, see e.g., \#16. This confirms our hypothesis that these people are not just economically rational but what we call relationally rational. We find evidence of relational rationality as being rational with two interdependent aspects in mind: economic utility and social relations. This means that people act from the perspective of the implicit social landscape defined by their culture, which influences their rationale. The differences between countries then are evidence not of different economic thinking but of different relational rationality.

\section{Discussion}

Recall from Sect. 3.1 that our first hypothesis H1 was: "To the extent that participants come from a culture of larger power distance, they will be more sensitive in their negotiation behaviour to their assumed social status in the game". The economic rationality analysis gives support for $\mathrm{H} 1$, but the relational rationality analysis does not. It is likely that larger samples might yield more clarity. All in all, however, power distance did not surface as the main cross-cultural issue for this game in this setting. Since the participants were self-selected, it cannot be excluded that potential participants with very hierarchical beliefs simply avoided the game.

Our second hypothesis $\mathrm{H} 2$ was: "The relationship between what participants say and what they do will be clearer in a comparison across countries than across individuals". The hypothesis received support from both the economic and the relational rationality analyses. For the latter, it was especially convincing that the ecological analysis yielded more alignment between statements and actions than did the pancultural analysis.

The qualitative analysis of the written comments by participants supplemented these insights with a glimpse at the variety of perceptions and interpretations brought to the game by its players. We conclude from these findings that, in this game, players are driven by relational rationality: they are rational from the perspective of the social world in which they live, with interpersonal relationships weighing heavily. 
The Lemon Car Game received the 800 participants in their own habitats from a long-tail distribution of countries. While the current sample size is still modest, the results do provide insights into our hypotheses.

However, it must be recognized that using nationality as a proxy for culture is crude. A stream of research in psychology attempts to operationalize culture at the level of the individual (Leung 1989). Such an approach would require separating the shared influence of culture from the individual-level influence of personality. However, in the absence of personality data, ways to relate culture to personality, or data about subcultures, the data does not allow us to address culture at individual level without confounding personality and culture.

For online games of this kind, the study confirms that players 'fill in the blanks' in culture-dependent ways, as is known for the world of face-to-face gaming simulation (Hofstede et al. 2010b). This implies that pilot studies to check for game perception are advisable before launching larger studies, as was found for studies with online story scenarios (Degens et al. 2017).

Indeed, a useful frame for reflection on the Lemon Car Game is the dimension of designer versus player. The results from the game suggest a case of "what I see is not what you get" (Degens et al. 2017), where 'I' stands for the authors, the designers of the game, and 'you' for the players. Degens et al. found, in an experiment, that designers were apt to wrongly anticipate how users from other countries would interpret their internet-based assignments.

A second useful frame is the dimension of rigour versus relevance. In the case of the Lemon Car Game, our working with a richer surrogate world than just, say, pure game theory, comes at a cost of rigour; but our adding the opportunity for players to explain their rationale, and our ability to connect player actions and statements, adds relevance to the game.

The game, and indeed any simple online game, is an abstraction that cannot be extrapolated to the real world without much caution. Isolating one dimension for the sake of experiment is a decidedly artificial method. In real life, the dimensions always operate as one whole - a cultural Gestalt - together with contextual factors and societal relational factors.

\section{Conclusion}

In cross-cultural business negotiation, culture is known to influence negotiation processes. As a lens to study this effect we deployed the Lemon Car Game, with the hypothesis that culture-dependent effects-which we frame as relational rationality-would modify the results that could be expected from the perspective of economic rationality.

We performed utility-based rationality analysis, individual-level pan-cultural analysis, ecological cross-cultural analysis, and qualitative motivational analysis. The limited numbers of respondents compared to the wide range of possible behaviours makes our conclusions tentative (Hofstede and Meijer 2007). Even with our modest current sample size, however, culture-bound patterns of variation can be 
discerned. As shown by the cross-cultural relational rationality analysis (Sect. 4.3.2), the top factor explaining variation in intentions and actions of the sellers had to do with relationship with the other party; for buyers this was the second most influential factor. The hypothetical social status had only limited effect on outcomes.

Our work on the Lemon Car Game highlights the complementary nature of three levels of analysis for teasing out cross-cultural differences. Section 4.2 shows that an individual-level analysis does not reveal easily interpretable patterns. The same holds for a pan-cultural analysis that lumps all participants into one group (Sect. 4.3.1). By grouping the participants by country, as in Sect. 4.3.2, we find a meaningful correlation between statements and actions. A strong outcome of our work is the contrast between player's up-front statements prior to playing the game and their behaviour in the game. In the pan-cultural, individual-level analysis, the stated intentions are not correlated with the actual negotiation behaviours for three out of four factors. In the ecological analysis per country, all three factors have both statements and actions. This shows that across a multi-national sample, value statements have little to say about actual negotiation behaviours.

The results presented in this article come from the online version of the Lemon Car Game. In the future we would like to use the computer-mediated game in the person-to-person modality-i.e., have two human players play via a screen, rather than face-to-face (e.g., Colored Trails (Ficici et al. 2008)) - as well as to explore how computer software agents can assist the negotiators (Baarslag et al. 2017). The growth in electronic negotiations in international business incentives this research (Melzer and Schoop 2016).

Acknowledgements Suggestions of the anonymous reviewers helped this work, particularly with the analysis. The authors also thank I. Bou-Hamad, A. Chereith, C. J. Haddad, C. Karam, V. M. de Souza, C. Tang, H. Tobi, B. Vastenhouw and S. Zeitouny. NYS acknowledges AUB University Research Board Award Number 288810 and Olayan School of Business OFFER Award Number C1_2013_2014.

Open Access This article is distributed under the terms of the Creative Commons Attribution 4.0 International License (http://creativecommons.org/licenses/by/4.0/), which permits unrestricted use, distribution, and reproduction in any medium, provided you give appropriate credit to the original author(s) and the source, provide a link to the Creative Commons license, and indicate if changes were made.

\section{Appendix: Participant Comments}

This Appendix gives a representative selection of player comments, unedited except for punctuation from the free-form text that the participants provided. Providing comments was optional for participants. Figure 6 provides the context of the game; comments were solicited at the 'end of the game' step.

\section{Comments About Game Objectives}

- To minimize the risk of a bad outcome. 
- Emotional responses typically occur when people are engaged interactively and often times people are offended by minimal leeway or movement by/of the seller.

- [It is] important for me to understand their rationale

- sellers would typically maximise their selling proposition in anticipation of bargaining downwards by buyers

- The seller always tries to give you incomplete if not false information in order to maximize her profits.

- I would also barter with the seller for the best price I could get.

- Best price counts

- the aim of the game was to get the best price for the car

- a seller is always searching for what's best for him

- Sellers especially in Lebanon where anyone and everyone is trying for the best for their own good have high intention to get the most money out of a deal regardless of product quality and so on because in most cases complaints after purchase tend to be disregarded and the blame is thrown all over.

- Second hand sellers are always trying to find a sucker to handle their undesired misfortunes.

\section{Comments About Identification with Game Role}

- Used car sale may be common in western world. However this is not often encountered in China or India I think

- Couldn't relate to the game because of age difference (22 vs. 42). I was made 20 years older. Could relate to the haggling part.

- For example all the prices from 2600 to 3200 are considered low and unreasonable in my country. Also the different in the prices (in the questions) is very small and does not make a sense: there is no notable different [sic] between 2600 then 2800 and 3000 . In my country all these prices are almost the same and mostly will be good even for a bad car.

- In the game yes in reality no. If something is not ok with the car I'd either fix it or mention it. I would still aim to get the highest price for it.

- We don't usually buy secondhand car in our country.

- I bought for my wife a secondhand car from her girlfriend emigrating to France. We knew her very well before.

- Because most of my relatives are liars and thieves. They know I am a trusting person and will try to take advantage of me.

\section{Comments About Reasoning and Reasons for Actions}

- The lemon is the lemon and the jewel is the jewel. There is a rational reason why the price will be different for identical cars. It's a question of the posture of the buyer as to which is on offer. I want what I want is a jewel buyer. I want the lowers price no matter what is the lemon buyer. 
- I would need to have the car checked out before agreeing to buy the car. My husband works for a dealership. In real life I am looking to buy a car for my teenage son. I am not interested in a person selling the car but rather the condition/quality of the car for the money paid.

- It is not fair to the buyer and I would not want someone to try and sell me a lemon as a jewel. If I want a jewel or they are willing to buy the car with full knowledge of its condition then we both get what we want and it is a fair deal. I also think I open myself to a lawsuit without full disclosure or by being misleading.

- In my opinion a second-hand car seller gets rid of their own unwanted car or resells one trying to make their best possible deal. Normally it is a lemon (worst case for a buyer) or a piece of property that the owner got weary with (neutral best case for a buyer). The seller has little constraint in their bargaining and hence has a lot more bargaining power over the buyer.

- It is always in someone's best interest to make a lemon pass off as a jewel. As I do not know the seller I have no basis of trust and so I do not take his statements at face value.

\section{Information Sought Beyond Economics}

- His profession-Goes to determine his mental and attitudinal positioning

- His/her income range. It gives me better chances to properly guess the item's true value.

- Financial status is very important

- why is he selling the car, to understand his intentions and bargaining position

- Reason for selling the car. How long they have had/used the car and what for. Whether they had done any regular maintenance on the car. Background about the seller such as his/her job. Reasons for selling can give an idea of how desperate they are to sell the car and this could possibly increase bargaining power. The manner in which they talk about the car can give an indication as to whether they cared for it treated it nicely are reluctant to let it go (but they have to because of personal circumstances) etc. A person's occupation indicates experience and to some extent makes it easier to categorize the seller which is of course not always true but is worth a shot.

- Initially I wanted to know whether they were a private seller or it was their job. Someone doing it for a living would have a lot of experience of cars/vehicles to draw on.

\section{Comments About Culture}

- traditional stereotypes associated with car sales in the US.

- My wife is from Cameroon. I know she will negotiate a lot more the price. I take the price as given more less negotiable. The price should reflect the real value of the car. If he sells the cars professionally or a hired seller and is trained in sales 
techniques. I'd prefer the cars owner who wants the money to buy another one. I would trust a trained sales person a lot less.

- I would prefer to find a control test of the car by a professional technician as an independent option not connected with any price as the real value of the car can shrink dramatically after test. Also I would like to know the nationality of the car-seller as in less developed countries the possibility to find an honest seller tends to zero while economically developed nations have built up rather trustful buyer-seller relationship.

- Although I was born and lived all my life in the Netherlands my parents were not born here. I do not belong to any of the large immigrant communities in the Netherlands but my cultural upbringing was probably still a-typical in some ways.

\section{Comments About Relationship Between Players}

- My trust depends on our friendship. If we are very good friends I'll definitely trust him/her. However if the relationship is just so so I may not trust the statement. I'd like to know if he/she is honest and the reason why he/she wants to sell the car.

- You can bargain for anyone especially not my blood

- Personally I would never buy a car from a relative as I don't want to have an emotional connection to neither price nor quality of the car.

- It depends on how much they 're selling it for. As a colleague I'd assume a better deal. Your friend will probably give you a good deal. If they ask exactly value for it it could go either way but if they are asking too little for it they really want to get it off their hands (and aren't considering something like donating) and it's more probably a bad idea.

- It's hard to tell but I would likely trust a friend. But verifying with an outside source would help maintain the friendship and ensure that even if the car was a lemon and it was stated a jewel by the inspection I would be more confidence in the fairness of the deal.

- In the game I am in tier $3(50-75 \%)$ of society. The seller is in tier 4 (75-100\%) of society. The car being sold was a maximum of $\$ 3200$. Why does a tier 4 person have a car of so little value? It must be a lemon.

\section{References}

Adair W, Brett J, Lempereur A, Okumura T, Shikirev P, Tinsley C, Lytle A (2004) Culture and negotiation strategy. Negot J 20(1):87-111

Akerlof GA (1970) The market for 'lemons': quality uncertainty and the market mechanism. Q J Econ 84(3):488-500

Baarslag T, Kaisers M, Gerding EH, Jonker CM, Gratch J (2017) When will negotiation agents be able to represent us? The challenges and opportunities for autonomous negotiators. In: Proceedings of the twenty-sixth international joint conference on artificial intelligence (IJCAI), pp 4684-4690

Barry B (2008) Negotiator affect: the state of the art (and the science). Group Decis Negot 17(1):97-105

Bots PWG, Hofstede GJ (2004) The takeover trio. Simul Gaming 35(4):505-516 
Degens N, Endrass B, Hofstede GJ, Beulens AJM, André E (2017) 'What I see is not what you get': why culture-specific behaviours for virtual characters should be user-tested across cultures. AI Soc 32(1):37-49

Engel C (2011) Dictator games: a meta study. Exp Econ 14(4):583-610

Ficici SG, Pfeffer A, Gal Y, Grosz BJ, Shieber SM (2008) Colored Trails: A multiagent system testbed for decision-making research. In: Proceedings of 7th international joint conference on autonomous agents and multiagent systems (AAMAS). ACM, New York, pp 1661-1662

Henrich J, McElreath R, Barr A, Ensminger J, Barrett C, Bolyanatz A, Cardenas JC, Gurven M, Gwako E, Henrich N, Lesorogol C, Marlowe F, Tracer D, Ziker J (2006) Costly punishment across human societies. Science 23:1767-1770

Hoffer GE, Pratt MD (1987) Used vehicles, lemons markets, and used car rules: some empirical evidence. J Consum Policy 10(4):409-414

Hofstede G (1995) Multilevel research of human systems: flowers, bouquets and gardens. Hum Syst Manag 14(3):207-217

Hofstede G (2001) Culture's consequences: comparing values, behaviors, institutions, and organizations across nations, 2nd edn. Sage, Thousand Oaks

Hofstede GJ (2006) Intrinsic and enforceable trust: A research agenda. In: Proceedings of 99th seminar of the European association of agricultural economists on trust and risk in business networks. Universität Bonn-ILB Press, Bonn, pp 15-24

Hofstede GJ, Meijer SA (2007) Collecting empirical data with games. In: Proceedings of 38th international simulation and gaming association conference (ISAGA). Eburon, Delft, pp 111-120

Hofstede GJ, Jonker CM, Meijer SA, Verwaart T (2006) Modelling trade and trust across cultures. In: Proceedings of 4th international conference on trust management (iTrust 2006). Springer, Berlin, pp 16-19

Hofstede GJ, Verwaart T, Jonker CM (2009a) Lemon Car Game. In: Proceedings of 39th international simulation and gaming association conference (ISAGA). Technologia, Kaunas, pp 39-46

Hofstede GJ, Jonker CM, Verwaart T (2009b) Modelling power distance in trade. In: David N, Sichman JS (eds) Multi-agent-based simulation IX, international workshop, MABS 2008, revised selected papers, LNAI 5269. Springer, Berlin, pp 1-16

Hofstede G, Hofstede GJ, Minkov M (2010a) Cultures and organizations, 3rd edn. McGraw-Hill, New York

Hofstede GJ, De Caluwé L, Peters V (2010b) Why simulation games work-in search of the active substance: a synthesis. Simul Gaming 41(6):824-843

Hofstede GJ, Jonker CM, Verwaart T (2012) Cultural differentiation of negotiating agents. Group Decis Negot 21(1):79-98

Irmer C, Druckman D (2009) Explaining negotiation outcomes: Process or context? Negot Confl Manag Res 2(3):209-235

Karagözoğlu E, Urhan UB (2017) The effect of stake size in experimental bargaining and distribution games: a survey. Group Decis Negot 26(2):285-325

Leung K (1989) Cross-cultural differences: individual-level versus culture-level analysis. Int J Psychol 24(6):703-719

Lincoln JR, Zeitz G (1980) Organizational properties from aggregate data: separating individual and structural effects. Am Sociol Rev 45:391-408

Melzer P, Schoop M (2016) The effects of personalised negotiation training on learning and performance in electronic negotiations. Group Decis Negot 25(6):1189-1210

Paolacci G, Chandler J, Ipeirotis PG (2010) Running experiments on Amazon Mechanical Turk. Judgm Decis Mak 5(5):411-419

Smith PB, Bond MH, Kagitcibasi C (2006) Understanding social psychology across cultures. Sage, Thousand Oaks

Teschner F, Gimpel H (2018) Crowd labor markets as platform for group decision and negotiation research: a comparison to laboratory experiments. Group Decis Negot 27(2):197-214

Turel O, Yuan Y (2008) You can't shake hands with clenched fists: potential effects of trust assessments on the adoption of e-negotiation services. Group Decis Negot 17(2):141-155

Verwaart D (2011) Agent-based modeling of culture's consequences for trade. Ph.D. Thesis, Delft University of Technology. http://resolver.tudelft.nl/uuid:e6a0231f-6851-4f51-97f1-55072caa3efe

Wong RS, Howard S (2017) Blinded by power: untangling mixed results regarding power and efficiency in negotiation. Group Decis Negot 26(2):215-245 


\section{Affiliations}

Gert Jan Hofstede ${ }^{1}$ (D) Catholijn M. Jonker ${ }^{2}$ (D) Tim Verwaart ${ }^{3}$. Neil Yorke-Smith ${ }^{2,4}$ (D)

Gert Jan Hofstede

gertjan.hofstede@wur.nl

Catholijn M. Jonker

c.m.jonker@tudelft.nl

Tim Verwaart

d.verwaart@xs4all.nl

1 Wageningen University, $6700 \mathrm{HB}$ Wageningen, The Netherlands

2 Delft University of Technology, 2600 GA Delft, The Netherlands

3 Wageningen University and Research, 6700 HB Wageningen, The Netherlands

4 American University of Beirut, Beirut, Lebanon 